\title{
ANEAPS of
}

PREFACE

\section{Geophysical monitorings at the Earth's polar regions}

The following collection of papers is dedicated to geophysical research and experiments conducted in the polar regions of the Earth, during a period centered around the last third International Polar Year (IPY, 2007-2009) and extending into succeeding years. The issues celebrating the IPY are intended to stimulate interest in the physical processes occurring at the polar regions, with the involvement of all the nations that collaborate and play key roles in these remote areas.

One of the main reasons for the great interest in polar science is that almost all the early signs of observable changes at planetary scale may be recognized primarily at the Earth's poles. This is one of the aspects that characterizes the polar regions as a natural and still undisturbed laboratory; an ideal place where international communities can improve the knowledge of mechanisms that are still incompletely understood.

Every individual discovery contributes in some way to the final value of the research; the following papers are a representative selection of the geophysical activities conducted in the Arctic and Antarctic regions. The four papers span a range of scientific topics, from volcanology, and seismology to the physics of the upper atmosphere. Rather than exhausting the myriad topics and sub-topics relevant to geophysics, the following papers describe methods of performing geophysical research in remote regions, and summarize the effort made in sharing technical and human resources, as well as the common desire to develop strategies for data collection, dissemination, and sharing.

It is probably unnecessary to state that polar regions are very extreme areas in terms of the external conditions in which humans, machines, and instruments must operate. Even a simple task, performed at a very low temperature and under very harsh environmental conditions, may require extreme effort, and special care is thus required in planning appropriate methodologies. In the following papers the reader can find descriptions of the field work performed, the logistic and scientific problems faced, the solutions found, and the principal breakthroughs made, in a sort of ideal journey into geophysical research in the Earth's polar regions.

\author{
Guest Editor \\ Domenico Di Mauro \\ Istituto Nazionale \\ di Geofisica e Vulcanologia, Rome, Italy
}

ANNALS OF GEOPHYSICS, 57, 3, 2014, SS0319;
doi:10.4401/ag- 6593 .
(C) 2014 by the Istituto Nazionale di Geofisica e Vulcanologia.
All rights reserved. 